\title{
Global health responsibilities in a Taliban-led Afghanistan
}

\section{To the Editor - The Taliban seizure of} power in Afghanistan has intensified an already dire humanitarian crisis. Although media attention has been focused on the evacuation from Kabul's international airport, the collapse of the Ashraf Ghani government and the Taliban advance have brought about a public health catastrophe.

Already confronting COVID-19, acute food insecurity and severe drought, Afghan public health infrastructure faces novel challenges, especially given that the Taliban campaign displaced more than half a million people ${ }^{1}$. Many healthcare workers have been forced to flee; others have not received salaries for months. Economic instability has jeopardized access to medicines, and most important, the Taliban movement has laid claim to the state and its healthcare services. When the Taliban ruled Afghanistan from 1996-2001, they showed little interest in public health, banning female patients from all 22 Kabul hospitals and relegating them to a poorly equipped facility in a city of 1.5 million ${ }^{2}$. Unsurprisingly, maternal mortality rose, reaching 1,450 deaths per 100,000 women in 2000, the highest in the world ${ }^{3}$. Since their return to power in August 2021, the Taliban again imposed restrictions on female mobility, endangering patient access to healthcare and further constraining the work of understaffed clinics. The Taliban's rhetoric has slightly shifted, but the health of all Afghans is demonstrably not their priority.

What steps can the international community take to avert a public health catastrophe in Afghanistan? The first step may be recognizing that progress in healthcare delivery is possible. For much of the past 40 years, Afghanistan has been embroiled in conflict, undermining the long-term development of its public health infrastructure, yet immense progress characterizes the last two decades. By 2018, access to health care within a two-hour radius expanded to $87 \%$ of the population ${ }^{4}$. Correspondingly, the maternal mortality rate decreased to 638 deaths per 100,000 women in 2017 , and life expectancy increased by about a decade to 63 years for both women and men between 2007 and 2017 (refs. ${ }^{3,5}$ ). While challenges remain, from polio infections to childhood malnutrition, recent history has shown the potential for sustained improvements in Afghan healthcare. The return of the Taliban threatens these gains.
While Western countries and international organizations have dedicated their efforts to evacuation and the suspension of aid $^{6,7}$, the international community has an obligation to provide humanitarian support to prevent cataclysmic devastation in Afghanistan, especially as much of the population has lost access to food, water, electricity and medical care. The suspension of foreign aid is particularly problematic as one-million children may die from severe acute malnutrition this year, and $90 \%$ of Afghan health facilities are at imminent risk of shutting down as they lack funds for staff or medical supplies ${ }^{8}$.

Offering unconditional aid to the Taliban undoubtedly risks conferring legitimacy upon a movement that seized power by force, and it remains unclear whether the Taliban will fob healthcare and other responsibilities onto foreign non-governmental organizations (NGOs) while primarily pursuing their ideological agenda. However, abandoning all support to Afghanistan would compound the crisis. An end to aid primarily harms the most vulnerable, especially given that in 2021 almost half of the Afghan population required humanitarian assistance 6 .

The argument for continued humanitarian aid is not only moral but also practical in nature given the potential development of more infectious and deadly SARS-CoV-2 variants in Afghanistan, as well as the potential resurgence of polio in the last frontier of the eradication effort. As such, global health organizations should devise alternative funding mechanisms to enable bodies such as the United Nations High Commissioner for Refugees to 'stay and deliver ${ }^{99}$ without propping up the Taliban regime, whether through funding NGOs directly, routing money through United Nations agencies, or creating independent organizations to manage funds.

Beyond the immediate crises, international aid efforts must directly empower the Afghan people to build a self-sustainable healthcare system. The history of foreign aid to Afghanistan has demonstrated that a facade of stability can be built over decades but collapse within days, underlining the need for more durable investments. Given that $80 \%$ of Afghanistan's budget has come from international aid in recent years, the Taliban will need foreign support to establish a functioning state ${ }^{6}$. This vulnerability gives international actors some leverage to negotiate concessions; they should use their finite political capital to prioritize the implementation of robust public health infrastructure that allows coordinated responses to emerging challenges while abiding by the humanitarian assistance principles: humanity, neutrality, impartiality and independence. Investments can also follow the BOLTO model, whereby donor funding is used to 'build, operate, lease and transfer ownership' of health infrastructure, such as a solar-powered system that now powers a surgical ward, a gynecology wing and more at a Lashkargah hospital ${ }^{10}$. Ultimately, investments in the foundations of the Afghan healthcare system may prove more sustainable and cost-effective than previous stop-gap aid.

Simultaneously, responding in an ethical fashion to the emerging Afghan refugee crisis will necessitate collaboration among numerous countries to expand their special immigrant visas and refugee admission programs, as well as to provide greater support to refugees on arrival. Under the humanitarian parole program, the United States is expected to resettle up to 95,000 Afghans, a welcome initial effort that must be exponentially expanded to meet the moment. Additionally, given that individuals granted humanitarian parole in the United States receive no public benefits, parolees should be granted refugee status to allow them Medicaid access and other critical benefits. Indeed, refugees must be purposefully integrated into care systems to avoid overutilization of emergency services and to eliminate barriers to primary care access.

Public health organizations can also involve refugee planners in the establishment of one-stop access points that help address the complex needs of refugees: first aid, infectious disease treatment and vaccinations in the short term, and support for mental health, trauma and chronic diseases in the long term. Such health considerations are critical for supportive refugee resettlement and may leave countries better positioned to sustainably host and integrate refugees into their societies.

Despite the commitments of the international community to protect global health and support a more peaceful world, 
rhetoric must soon translate into action to prevent the disastrous consequences of an even greater humanitarian crisis in Afghanistan. Taliban rule threatens to reverse significant achievements in health equity and public health infrastructure over the past two decades, and international aid organizations and states must seek out innovative approaches to avoid such regression. These responsibilities include comprehensive refugee resettlement and sustainable healthcare aid deployment to protect the vulnerable and reduce dependency over the long term. While Western policies have abandoned Afghanistan to the Taliban, the world cannot abandon the Afghan people; the stakes to global health are too high.
Bhav Jain (D)', Simar S. Bajaj(D),

Mariam Noorulhuda ${ }^{3}$ and Robert D. Crews ${ }^{3 凶}$

${ }^{1}$ Massachusetts Institute of Technology, Cambridge,

MA, USA. ${ }^{2}$ Department of History of Science,

Harvard University, Cambridge, MA, USA.

${ }^{3}$ Department of History, Stanford University,

Stanford, CA, USA.

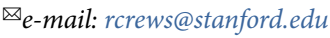

Published online: 8 November 2021

https://doi.org/10.1038/s41591-021-01547-8

References

1. Westfall S. Internal displacement crisis in Afghanistan looms in wake of Taliban takeover. The Washington Post (20 August 2021).

2. Dubitsky, S. Hum. Rights Br. 6, 10-11 (1999).

3. World Health Organization. https://www.who.int/teams/ sexual-and-reproductive-health-and-research-(srh)/overview (accessed 20 August 2021).
4. UK Visas and Immigration. https://www.gov.uk/government/ publications/afghanistan-country-policy-and-information-notes 2020).

5. Cousins, S. Lancet 398, 197-198 (2021)

6. Goodkind, N. Countries race to block Taliban from billions in Afghan funds. Fortune (18 August 2021)

7. Rappeport, A. The World Bank is freezing aid disbursements to Afghanistan. The New York Times (24 August 2021).

8. Farge, E. Hundreds of health centres at risk of closure inAfghanistan - WHO. Reuters (6 September 2021)

9. Mantoo, S. UNHCR The UN Refugee Agency. https://www.unhcr. org/en-us/news/briefing/2021/8/611f61824/unhcr-warnshumanitarian-needs-afghanistan-forgotten.html (20 August 2021).

10. Glinski S. A loan, not a gift: merging business and aid in Afghanistan. The New Humanitarian (17 June 2019).

\section{Author contributions}

B.J. and S.S.B. contributed equally to this manuscript as co-first-authors. B.J., S.S.B. and M.N. drafted the manuscript. R.D.C. conceptualized the manuscript topic, provided supervision and edited the manuscript.

Competing interests

The authors declare no competing interests.

\section{The lesson of ivermectin: meta-analyses based on summary data alone are inherently unreliable}

To the Editor - The global demand for prophylactic and treatment options for COVID-19 has in turn created a demand for both randomized clinical trials, and the synthesis of those trials into meta-analyses by systematic review. This process has been fraught, and has demonstrated the inherent risks in current approaches and accepted standards of quantitative evidence synthesis when dealing with high volumes of recent, often unpublished trial data of variable quality.

Research into the use of ivermectin (a drug that has an established safety and efficacy record in many parasitic diseases) for the treatment and/or prophylaxis of COVID-19 has illustrated this problem well. Recently, we described flaws in one randomized control trial of ivermectin ${ }^{1}$, the results of which represented more than $10 \%$ of the overall effect in at least two major meta-analyses ${ }^{2,3}$. We described several irregularities in the data that could not be consistent with them being experimentally derived $^{4}$. That study has now been withdrawn by the preprint server ${ }^{5}$ on which it was hosted. We also raised concerns about unexpected stratification across baseline variables in another randomized controlled trial for ivermectin ${ }^{6}$, which were highly suggestive of randomization failure. We have requested data from the authors but, as of
6 September 2021, have not yet received a response. This second ivermectin study has now been published ${ }^{6}$, and there is still no response from the authors in a request for data.

The authors of one recently published meta-analysis of ivermectin for COVID-193 have publicly stated that they will now reanalyze and republish their now-retracted meta-analysis and will no longer include either of the two papers just mentioned. As these two papers ${ }^{1,6}$ were the only studies included in that meta-analysis to demonstrate an independently significant reduction in mortality, the revision will probably show no mortality benefit for ivermectin.

Several other studies that claim a clinical benefit for ivermectin are similarly fraught, and contain impossible numbers in their results, unexplainable mismatches between trial registry updates and published patient demographics, purported timelines that are not consistent with the veracity of the data collection, and substantial methodological weaknesses. We expect further studies supporting ivermectin to be withdrawn over the coming months.

Since the above primary studies were published, many hundreds of thousands of patients ${ }^{7}$ have been dosed with ivermectin, relying on an evidence base that has substantially evaporated under close scrutiny.

Relying on low-quality or questionable studies in the current global climate presents severe and immediate harms. The enormous impact of COVID-19 and the consequent urgent need to demonstrate the clinical efficacy of new therapeutic options provides fertile ground for even poorly evidenced claims of efficacy to be amplified, both in the scientific literature and on social media. This context can lead to the rapid translation of almost any apparently favorable conclusion from a relatively weak trial or set of trials into widespread clinical practice and public policy.

We believe that this situation requires immediate remediation. The most salient change required is a change in perspective on the part of both primary researchers and those who bring together the results of individual studies to draw wider conclusions. Specifically, we propose that clinical research should be seen as a contribution of data toward a larger omnibus question rather than an assemblage of summary statistics. Most, if not all, of the flaws described above would have been immediately detected if meta-analyses were performed on an individual patient data (IPD) basis. In particular, irregularities 